\title{
INVESTIGACIŌN
}




\section{LA MUJER MADRE Y LA MAL CASADA: PERCEPCIŌN DEL MATRIMONIO EN EL NORTE DE FRANCIA «CIRCA» 1100 *}

\section{Georges Duby}

En el norte de Francia el conflicto entre las dos concepciones del matrimonio sostenidas por los laicos y por los jefes de la Iglesia atravesaba un grave momento en torno al 1100 . El episcopado había terminado su tarea de autorreforma. Se purificó y consolidó sus principios y estructuras intelectuales apoyado en la diligente tarea de los canonistas. Los obispos remodelaron la vida social operando a través del mayor mecanismo: la institución matrimonial. Prohibieron casarse a los eclesiásticos desde que creyeron que la abstinencia sexual era una garantía para la superioridad, la cual dispuso a los clérigos en la cima de la jerarquía de las condiciones terrenales. A la inversa, los obispos prescribieron el matrimonio a los laicos: para controlarlos mejor, concederles una estructura y limitar su excesos. Les impusieron la formación de parejas de acuerdo con las reglas y los principios progresivamente santificados con la evolución del ritual y del pensamiento religioso. Reafirmaron la indisolubilidad de la unión conyugal; impusieron la exogamia en nombre de un ilimitado concepto de incesto; repitieron que procrear era la única justificación para la copulación soñando con su-

-Este artículo es la versión castellana de aThe Matron and the Mis-Married Woman: Percepcions of Marriage in Northern France "circa" 1100*, publicado en inglés en Soctal and Ideas: Essays in Honour of R. H. Hilton, ed. Aston, Coss, Dyer and Thirsk. Past and Present Society, 1983. La traducción ha corrido a cargo de Juan Ruiz Fré. 
primir todo placer en este acto. De hecho, el orden que los prelados buscaban decididamente imponer no era una respuesta al desorden. Se enfrentaron con un orden diferente, con otra modalidad, con otras prácticas que se encontraban estrictamente reguladas, pero no fueron creadas para salvar almas, sino más bien con la intención de facilitar la reproducción de las relaciones sociales entro de las estructuras existentes. La moral secular y las prácticas matrimoniales se fueron haciendo más rígidas a finales del siglo $\mathrm{XI}$, al menos entre la aristocracia, única sección de la sociedad en la distribución del poder. Enfrentados con las admoniciones episcopales, los nobles y caballeros se doblegaron. No fue solamente por su deseo de gozar de la vida. Si ellos eran cabeza de familia, responsables del destino de su linaje, reclamaban el derecho a repudiar a sus esposas si no les podían dar un heredero varón, a casarse con sus primas si la unión era en interés de la herencia. Si eran solteros, reclamaban el derecho a practicar todos los rituales eróticos apropiados a su kjuventud \$. La culminación de la reforma gregoriana agudizó el enfrentamiento entre los dos sistemas éti$\cos$. La lucha fue ferozmente conducida por los jefes detentadores del poder religioso: el papa, desde lejos, los legados que intervenían directamente y algunos canonistas como Yvo de Chartres que estaban en el asunto, los condujeron según los distintos grados sociales. Forzaron a los grandes a dar ejemplo. El rey fue el primero que debía seguir sus instrucciones; esto dió lugar a espectaculares acontecimientos como la excomunión tres veces renovada del capeto Felipe I. Para propagar un modelo conyugal desarrollaron una enseñanza pastoral del buen matrimonio. Entre los instrumentos más efectivos de esta propaganda y al mismo tiempo el más accesible al historiador se encuentran las narraciones edificantes, las biografías de algunos héroes cuyas conductas debían de ser imitadas por los fieles y a este propósito debían de ocupar un puesto entre los santos.

A primera vista, las vidas de santos parecen poco atractivas por la rigidez del género literario y el peso de la tradición formal. Pero estos escritos resultan muy instructivos si son tomados por lo que fueron, es decir, como una sofisticada arma en la batalla ideológica. Revelan como la memoria de una experiencia era manipulada, según las necesidades de la causa; desmembrada y reordenada para producir una función de adoctrinamiento. He escogido dos de estos textos, uno escrito a comienzos (1085) y el otro a finales 
(1130-36) de este decisivo período en la historia del matrimonio en nuestra cultura. Ambos procedentes de la misma región: en los límites occidentales del principado de Flandes, entre Boulogne y Brujas; y elaborados en el mismo tipo de taller: los scriptoria de los monasterios benedictinos. Cada uno presenta a una mujer para la veneración de los fieles. Ambos describen una imagn modelo de la condición femenina y exigen que el matrimonio transcurra para los laicos dentro del camino trazado por las autoridades eclesiásticas hasta el punto de revelar dos posiciones contrarias, ya sea por lo que dicen como por lo que omiten, por la forma de adaptar los hechos concretos de las vidas, de embellecerlos o de oscurecerlos.

Es mejor comenzar por el texto tardío ya que es menos rico y paradójicamente más tradicional. Relata las virtudes de la condesa Ida de Boulogne. La biografía fue compuesta unos veinte años después de la muerte de la heroína en 1113 en el monasterio de Vasconvilliers, que ella misma había reformado y enriquecido con buenos monjes cluniacenses ${ }^{1}$. Alli, donde su cuerpo fue enterrado después de feroces disputas, creció un culto alrededor de su túmulo en medio de las litúrgias funerarias. Según las normas, la narración comienza con la *infancia donde los signos anunciaban ya una vida excepcional y notable con esas virtudes que se transmitían por la sangre a aquellos de buen matrimonio. De ahí pasa a la vida adulta y a los milagros que la marcaron y luego llega a su muerte, terminando con los milagros acaecidos post-mortem. Todo ello forma una especie de edossier», bien equipado de pruebas (las que incluyen el olor de santidad emitido de la tumba cuando esta fue abierta en una fecha incierta) que intentaban justificar el culto oficial ya que la jerarquía eclesiástica seguía siempre meticulosamente los procedimientos de canonización.

Nacida hacia 1040, Ida fue una gran dama. Hija mayor del duque de Loithier (baja Lotaringia), un príncipe del orden más elevado y de sho menos eminente madre, fue favorecida con un nacimiento con poder (potestas) y riqueza (divitae), los dos atributos

1 Acta sanctorum... loannes Bollandus et altera, X. Aprilis II (Antwerp, 1675), pp. 141.5. 
de la nobleza. Todas las cosas la predisponían a la magnanimidad. La Vita muestra perfecto respeto al orden establecido al presuponer que providencialmente nobles y ricos son buenos y al asumir una correlación natural entre la jerarquía de valores temporales y aquella de valores espírituales. El espíritu cluniacense de esta obra evita sugerir que Ida pudo haber soñado con humillarse a sí misma dejando su alta posición o que hubiese deseado sufrir físicamente o que hubiese mortificado su propia carne. Esta santa no era ni mártir ascética ni una de esas fanáticas que deseaban ser pobtes a cualquier precio. Fué únicamente una esposa completamente feliz. La moral predicada aquí es la de la realizaciōn de la feminidad en el matrimonio.

La biografía alcanza su punto culminante en el momento en que Ida, virgen, se convierte en esposa a la edad apropiada (1057). El autor se esfuerza en mostrar que el cambio se efectuó de manera correcta, acorde con las conveniencias morales y sociales. El hombre que desfloró a Ida era necesariamente de su rango -un shéroes, de «muy buen nacimiento», ede la sangre de Carlomagnos, de extraordinaria fama. Se pone énfasis en subravar también la necesidad del matrimonio entre iguales como la importancia de la reputación, que permite el matrimonio ea la gente de valors. En efeto, fue la reputación de la muchacha, manifestada en su moral, su belleza, pero sobre todo en ela dignidad de su nacimientow lo que atrajo a Eustaquio II, conde Boulogne ${ }^{2}$, que había quedado viudo al morir una de las hermanas de Eduardo el Confesor. Como no tenía heredero legítimo necesitaba ineludiblemente conseguir una esposa. Tomó a una, pero decentemente, sin rapto ni seducción; enviando mensajeros al padre de ella, responsable del matrimonio y se dejó aconsejar. Ida fue acedidas por sus padres, entonces escoltada por miembros de las dos familias fue conducida a Boulogne donde el novio la esperaba. Alli tuvo lugar la ceremonia matrimonial, solemnemente, ade acuerdo con las prácticas de la iglesia católicas (pro more ecclesiae catholicae), como dice el texto. ¿Es quizás esto una alusión a la bendición nupcial? En 1130 este ritual había echado raíces en la región, aunque nada indica que hubiera sido introducido alli en el año 1057.

2 Según datos recientes, fue un descendiente de los carolingios por línea ma. terna, el nieto de Carlos de Lorena. Nada se conoce de su padre, probablemente un bomme noueveu. 
A partir de entonces, Ida aparece como esposa (conjux) desplegando su excelente moral en el matrimonio (virtus in conjugio), apareciendo consecuentemente como el parangón de las buenas esposas. En primer lugar, es sumisa, con su marido, quien la sostiene, la guia, la dirige hacia lo mejor. Es igualmente devota, pero «en armonía con su esposo y sus deseos». ¿Se puede pensar que una mujer pudiera alcanzar la santidad a pesar de su marido? También era obediente, pero ante todo discreta (esto es, con la discretio cluniacense) en la dirección de su casa y en el trato con los huéspedes; se conservaba «castas en las relaciones íntimas con los nobles. De hecho la castidad formaba el buen matrimonio. Así, ade acuerdo con los preceptos apostólicos» Ida dio a luz esirviéndose del hombre pero sin poseerlow. Ser madre fue su principal virtud. Trajo al mundo tres hijos (el texto nada dice acerca de las hijas); el segundo de ellos fue Godofredo de Bouillon y el tercero fue Balduino, rey de Jersusalén. La acención puesta en Ida al final de su vida y el olor de santidad emanado de su tumba se debieron sin duda al destino de estos dos hijos; al hecho de que los dos primeros gobernadores de Tierra Santa habían salido de su matriz. La santidad de la unión conyugal se midió por la gloria de los varones, fruto de esa unión. De esa gloria Ida fue consciente en su adolescencia. Una noche cuando ase había entregado al sueño» vio el sol descender del cielo y detenerse por un momento en su pecho. La hagiografía se deleita con presagios $y$, con deleite, evoca los sueños. A decir verdad, el sueño de Ida estaba peligrosamente coloreado de erotismo preadolescente. El escritor monástico se dio cuenta de ello y tuvo cuidado. Por eso dice que Ida estaba soñando, pero con su espíritu enfocado «hacia las cosas celestiales». El sueño no describe su descenso al placer, proclama que la virgen deseaba ser madre y que el fruto de su vientre iba a ser bendito; una santa maternidad. Toda la vita se organiza para celebrar el nacimiento de los hijos.

Genus, gignere, generositas: estos conceptos acentúan la primera parte de la narración. Notemos su connotación carnal: recalcan la sangre, la buena sangre, el noble nacimiento. La función de Ida - como la función de todas las mujeres introducidas por el rito matrimonial dentro de las casas nobles - era la de formar *por la gracia de Dios» el eslabón de una genealogía ${ }^{3}$. Dio a luz y ali-

${ }_{3}$ Tal es como aparece en las genealogías de los condes de Boulogne, excelente- 
mentó varones. No es elogiada por haber nutrido espiritualmente a sus hijos, ni por instruirlos, ni por haberlos preparado y educado para las hazañas que les dieron fama. Pero en cambio es alabada por haberlos amamantado, impidiendo que ellos tomaran leche de otros pechos que hubieran podido econtaminarlos de malas costumbres».

Se dice también que Ida continuó su función procreadora de otro modo. Después de quedar viuda (hacia 1070) y *privada del consuelo de un hombres, fue «consolada por la nobleza de sus hijos» y enriquecida por el amor del más allá. Bajo la autoridad de su hijo mayor, Eustaquio III que había sucedido a su padre como cabeza del linaje, perpetuó sus virtudes que, como siempre, se manifestaron por la reproduccióin, aunque en esta ocasión ya no fuese corporal. Así, a partir de ese momento, Ida dio a luz por la vía de la riqueza, más exactamente por la vida de su dinero. Después de la muerte de su marido y de su padre llegó a un acuerdo con sus allegados para vender todos sus alodios. Utilizó este dinero, de nuevo surgido del clan (genus) paterno para tener nuevos hijos, en esta ocasión espirituales: monjes. Como es natural no actuó sola, sino en armonía con el varón en cuyo dominio estaba. Con el «consejos y la sayudas de su hijo efertilizós la región de Boulogne reconstruyendo, reformando y fundando sucesivamente tres monasterios. Estos fueron monasterios de hombres; carnal o no, ella sólo tuvo descendencia masculina. Pero no se hizo monja; habiendo desaparecido su esposo mortal se dispuso a unirse con el esposo inmortal en una vida de castidad y celibato. Gradualmente cambió la protección de su hijo por la de otra familia espiritual. Hugo de Cluny la adoptó «como una hijas, aunque fue a vivir allí en estado de subordinación, sometida a los hombres. De igual modo, cuando trasladó su residencia junto al último monasterio que había construído, la Capilla de Santa María, lo hizo bajo la autoridad del hermano abad y rodeada de sus seguidores. Cantando salmos, pero «con moderación», se convirtió en madre adoptiva, alimentando a los pobres, alimentando a la comunidad mo-

mente editadas por L. Genicot, Etudes sur les principastés lotharingiennes, (Lovaina, 1975), cap. 10, «Princes territoriaux et sang carolingien. La Genealogia comitum Bulonensiumv. La más antigua de estas fechas, 1082-1087, cuando su segundo hijo, Godofredo, aún no había heredado salvo el nombre y las ambiciones de su abuelo y su tío materno. Ida es la única mujer de esa época en esta genealogía que merece un panegírico individual. 
nástica: «Sirviendo» a los hombres como convenía que las mujeres no dejaran de hacer. Dado que la maternidad era la mayor virtud (virtus) de esta santa, vuelve a aparecet en el peculiar carácter de los dos milagros que se le atribuyeron. Realizó el primero durante su estancia en el monasterio de la Capilla. Entre la gente que vivía de su generosidad había una pequeña niña sordomuda. Un día de fiesta, en el servicio de mañana, la madre llevó a la niña a la Iglesia en el séquito de la condesa, hacía frío y la pequeña temblaba. Se acurrucó bajo el manto de Ida y fue como si el olor de la vestimenta le proporcionase nueva vida. Comenzó a oir y a hablar. ¿Cuáles fueron sus primeras palabras? « Mater, mater!». No obstante, aquella persona volvió a pecar a pesar de la prebenda del abad. Concibió y dio a luz, perdiendo no sólo la virginidad sino tambien la salud. Ida la libró por dos veces de la flaqueza en la que por dos ocasiones volvió a reincidir, purificando la pecaminosa maternidad de la que la joven era culpable. De nuevo Ida volvió a ser una madre adoptiva hasta que se restauró la prebenda con el nuevo nacimiento. El otro milagro tuvo lugar en su sepultura, probablemente poco antes de ser escrita la vita. Otra vez una mujer se benefició de ello. Matilde, hija de Eustaquio III y nieta de la propia Ida. Afligida por una mala fiebre, *confiando y asumiendo la santidad de la beatas llegó hasta la tumba de Ida como la primera peregrina y fue curada. Su abuela prefirió proyectar su poder taumatúrgico en su propio linaje: como una especie de árbol de Jesé brotando de su generosa matriz.

Es obvio que la vida de esta princesa no tuvo nada de excepcional. A finales del siglo XI era normal que las jóvenes de su rango social se casaran con valientes guerreros, dieran a luz a otros y al enviudar hicieran donaciones a los monasterios con la aprobación de sus hijos primogénitos para, finalmente, unirse a la liturgia monástica. No hay nada excepcional en esto, salvo el haber traído al mundo a Godofredo de Bouillon ${ }^{4}$. ¿Habrían sido los restos de Ida objeto de disputa en 1113 si sus dos hijos no hubieran sido tan ilustres? ¿Se habría abierto años más tarde su sepultura? ¿Se le habría declarado santa hacia el año 1130 ? El instigador de este reco-

4 Conocemos las leyendas que florecieron en torno a la persona del primer adefensors del Santo Sepulcro, La fábula del cisne parece haber surgido a partir de lo que se contraba acerca de él y de su hermano hacia 1184: GUIUERMO DE TY. RE. Historia rerum in partibus transmarinis, 1 vol. in 2 (Recueil des histoires des croisades. Historiens occidentaux, I, Paris, 1844, pp, 571-2). 
nocimiento oficial fue probablemente la misma Matilde curada por su abuela desde la tumba. Heredera del condado de Boulogne, Matilde se casó con Esteban de Blois. Su otra abuela fue Margarita de Escocia, considerada muy pronto como una santa y manifestando, en su primera biografía (1093-95) que había aceptado el matrimonio con el sólo propósito de convertirse en madre. El culto a Santa Margarita se desarrolló al mismo tiempo que el de Eduardo el Confesor por Adela Matilde, esposa del rey Enrique I y tia de Esteban de Blois y sobre todo tía materna de Matilde de Boulogne $e^{5}$. Probablemente Matilde siguió el ejemplo de su tía materna y encargó el panegírico de Ida a los monjes de Vasconvilliers cuando se preparaba el traslado de la sede episcopal desde Morinie a Boulogne y cuando su esposo veía crecer las esperanzas de suceder al rey de Inglaterra. Creo que los monjes debieron encontrarse algo molestos e incómodos al encontrar en el «dossier sólo el talento de la procreación como el principal argumento de santidad. Esto se trasluce en el prólogo en donde se intenta justificar lo que se va a narrar. El mundo, dice el autor, se acerca a su final. Los ataques de Satán se multiplican. ¿Qué se puede hacer exceptuando las oraciones y las virtudes de los santos? Felizmente la providencia ha distribuído santidad en todas las clases del orden social; toda mujer podía encontrarse entre los santos, toda mujer casada a condición naturalmente de que fuera madre. Entonces podía suceder que estuvieran sinscritos en el libro de la vida por sus virtudes y por las de sus hijos». El biógrafo, venciendo prolongadas reservas, juzgó que era necesario presentar lo bueno del estado matrimonial. Para justificar el matrimonio cita a Pablo: «Es mejor casarse que consumirse» (melius est nubere quam uri). El matrimonio era el remedio a la lujuria. Recordó que, «de acuerdo con la ley», el matrimonio era exaltado por la prolífera fertilidad. Finalmente, afirmó que se debía vivir en la castidad «sin la cual nada es bueno», es decir, «la virginidad es buena, pero está probado que más grande es la castidad después de dar a luzs. Alguno de estos principios fueron impuestos como guía y para un benedictino le resulta posible establecer que una esposa pueda llegar a santa. Todo esto lo relaciona el biógrafo de forma discreta con la da-

s D. BAKER, \&"A Nursey of Saints" $"$ : St. Margaret of Scotland Reconsidered», en D. Baker (ed.) Stzdies in Cburch History, subsidia, 1 Medieval Women (Oxford, 1978), pp. 119-1141. 
ma cluniacense, sin ofensa alguna y con un alto sentido de las conveniencias sociales, propone una estampa del buen matrimonio, completamente conforme con las enseñanzas de las escrituras y San Agustín. El biógrafo, al estar al servicio de los intereses de una casa de la alta nobleza, tuvo cuidado de armonizar el cjemplo propuesto y el código de valores al que estaba adscrita la aristocracia. Los dos sistemas de moralidad, el de la Iglesia y el de las dinastías, se encuentran conciliados aquí. No estoy hablando sólo de la celebración de la riqueza y del poder sino del modo de ilustrar las hazañas de la heroína. Los dos modelos de conducta están configurados para que coincidan fundamentalmente en dos niveles: primero, se asegura que la condición de la mujer consiste en estar dominada: por su padre que la da a quien le place; por su marido que la controla y dirige; luego por su hijo mayor y, finalmente, cuando éste la echa de la casa junto a aquellos que son una carga, por los monjes de la familia del monasterio - una de cuyas funciones es precisamente abrir las puertas a las mujeres de los linajes que han sido marginadas al dejar de ser útiles. Segundo, aquí también hay un acuerdo en el principio que la esposa está destinada a cooperar en la gloria del linaje, por la procreación de hijos, con muchachos que deberán de ser valientes. Proclamar la imagen de la feminidad y la unión conyugal, mantenida por todos los cabezas de familias nobles a comienzos del siglo XII, de acuerdo con el plan divino, era seguramente el mejor camino para que de forma discreta en passant, se reconociera sin énfasis que el pacto sólo podía realizarse conforme a alas prácticas de la Iglesia católica» y que era de desear que los esposos mostraran al menos la apariencia de castidad.

Unos cincuenta años más tarde se había presentado otro ejemplo en un texto, o mejor, en dos textos diferentes, dos versiones de la misma vita datadas en el siglo XI y que han sido conservadas hasta hoy. Este ejemplo es diferente porque el sistema de imágenes al cual pretende corresponder no era, a mi modo de ver, aristócratico sino popular. La heroína, Godelive, realmente es bien nacida, de «célebres padres». Tiene nombre teutónico, el segundo biógrafo creyó necesario ofrecer una traducción: «Querida a Dios» (Cara Deo). Este nombre se adecúa bien a una santa de tal forma 
que uno está tentado a preguntarse si el nombre, e incluso la propia persona, es un mito. Pero nada más cierto, Godelive existió realmente. Los datos acerca de su descendencia son indefectiblemente precisos. Su padre, Heinfridus de Londefort, en el Boulonnais, es nombrado en los documentos de la época. Fue caballero de Eustaquio de Boulogne, esposo de Ida, aunque más humilde que Eustaquio y su familia. De todos modos ambos estaban situados sobre la gente ordinaria - por encima de la estricta línea que el modo de producción señorial traza entre el dominante y el dominado. Si he usado la expresión popular es porque la biografia que analizo no fue escrita por requerimiento de la ilustre familia a los monjes de un Eigenkloster. La devoción inspirada por Godelive surgió en Ghistelle, a diez kilómetros de Brujas, la ciudad de la costa de Flandes donde fue enterrada. Su primer biógrafo nos cuenta lo que le aconteció: «por presión de muchos fieless. Él no miente. Lo que nos cuenta acerca de las formas de piedad que tuvieron lugar en la tumba y de los milagros que demuestran esa evidencia confirman que el culto había nacido entre los campesinos de su tiempo. El mismo vió como la tierra adyacente a la tumba se transformaba milagrosamente en piedras blancas y vio como la gente se las llevaba a sus hogares scon mucha devoción y allí se convertían en joyas». Igualmente vio a la gente enferma de fiebre, a inválidos, ir a tomar agua del pozo donde Godelive fue lanzada. Los jefes de la Iglesia forzados por el fervor popular cedieron y el treinta de julio de 1084 , en Ghistelle, el obispo de NoyonTournai, Rabedot II, instituyó la elevación de las reliquias de una mujer que había muerto allí, tal vez catorce años antes. Hizo esto al tiempo que encargó la iglesia de Dudenbourg a San Arnulfo de Soissons para establecer allí a los benedictinos de San Bertín y con la misma intención de fortalecer las estructuras eclesiásticas en las fronteras de su diócesis. El prelado quiso adaptar la leyenda para que sirviera en el intento de levantar la moralidad de la población que era todavía muy primitiva. La manipulación resulta evidente, aunque quedan huellas de la narración original. Aparecen con claridad en la versión de la vita que los bolandistas publicaron de un manuscrito procedente de la abadía de Dudenbourg, después de la canonización ${ }^{6}$ y mucho más claramente en el texto que per-

6 Acta sanctorum... Ioannes Bollandus et altera, XXVII, Julii, II (Antwer, 1721) pp. $403 \mathrm{ss}$. 
feccionó esa adaptación - en el informe que Drogon, monje de Bergues-St-Winock escribió antes de la intervención del obispo de Noyon y que prepara el camino a la canonización?

¿Cuánto tiempo duró el proceso de reorganización y oficializa. ción del culto? ¿La elevación de las reliquias no estaría desde un principio orientada a detener la religiosidad heterodoxa? Esta hipótesis fue formulada por Jacques Le Goff cuando comentaba este documento en uno de mis seminarios. En el siglo XII, puso él de relieve, hay pocos datos en los textos sobre brujería. ¿Acaso la Iglesia en este tiempo no acogería a esas mujeres en su institución (al menos aquellas cuya memoria estaba viva entre los humildes) por haber perecido trágicamente, asesinadas por los ministeriales, los represivos agentes del poder civil? ¿fueron sistemáticamente exorcizadas por la *conversión» de su reputación y convertidas en santas? No creo necesario Jlevar tan lejos esta conjerura pero el hecho consiste en que si Godelive fue canonizada, tal vez pudo ser para cambiar toda la controversia existente en la veneración que la tenían. Dos de sus cuatro milagros recordados por el primer biógrafo sirven para reafirmar esta suposición. Godelive fue curandera, curó parálisis. Fue en ayuda de un hombre y una mujer a quienes el acielo» había castigado por trabajar en tiempo prohibido, según las autoridades eclesiásticas. El hombre estaba segando un sábado por la tarde y su mano quedó aferrada a las espigas de trigo. La mujer, en un día de fiesta después de misa, estaba removiendo un caldero de tinte con un palo y éste quedó pegado a su mano. El que Godelive hubiera liberado esas dos manos laboriosas, suprimiendo los efectos de la ira divina puso al pueblo de su lado. Superó las excomuniones de los sacerdotes. ¿No sería alabada como la campeona de la resistencia frente a la opresión clerical? Este es el incentivo para detectar los fragmentos de un discurso diferente, popular, bajo las edificantes y tranquilizadoras frases de la vita. Al igual que la biografía de Santa Ida, ésta no fue remodelada con una sola intención, de modo que, aunque en otro ámbito social, sirvió para propagar la moralidad eclesiástica del matrimonio.

7 Editado por Fr. Coens a partir del manuscrito de St-Omer procedente de la abadía de Clairmarais: La vie ancienne de sainte Godelive de Ghistelles par Drogon de Bergues, ed. M. Coens (Analecta Bollandiana, XIIV, Bruselas, 1926. pp. $102-37$. 
En una tipología de la santidad, la hija de Heinfridus, caballero de Boulogne, encontraría su lugar entre los mártires. Pero, ¿podrá ser contada entre las vírgenes? Su virginidad, escribieron los bolandistas, no ofrece ninguna duda; en Ghistelle fue considerada siempre como virgen. Nada dicen estos manuscritos acerca de la virginidad. Para sus autores - bastante notables - ésta no es una característica importante. Ellos enfatizan ante todo el martirio. En todo caso se trata del martirio de una esposa. Godelive fue víctima de un mal matrimonio. Las hagiografías lo proclaman con fuerza y claridad, con la intención inter alia de presentar en el negativo lo que constituye un buen matrimonio. Sólo una vez se aplica la palabra virgo a Godelive, y fue en ocasión de la descripción de su condición antes de que sus padres le dieran un marido. Su destino, como el de todas las jóvenes, era el del estar casada al final de su infancia (pueritia). A diferencia del caso de Ida, desde un principio se emplearon procedimientos corruptos, desde los propios esponsales (desponsatio) hasta la conclusión del acuerdo. Modesta y devota como son todas las santas en la infancia, ella fue solicitada por multitud de pretendientes que «ardían de amor», como dicen los textos. En efecto, ambos textos, refundidos de acuerdo con los originales, conceden un lugar importante al deseo físico y a la atracción de la joven muchacha. Su único defecto consistía en ser morena, con cabello y cejas negras. Pero Drogon lo matizó: puesto que como contraste, decía, «su piel parecía más blancav lo que la colocó en un puesto de honor entre muchas mujeres y sedujo a los hombres jóvenes (juvenes). Bertolf era «poderoso», de distinguida cuna por descendencia directa, uno de los oficiales del conde de Flandes en el distrito de Brujas ${ }^{8}$. El fue quien la consiguió. Godelive no pudo escogerlo por sí misma y él, por otro lado, no le habló a ella sino a sus padres ya que eran ellos quienes se la podían entregar. El acuerdo fue ilegal por ambas partes. En primer lugar, Bertolf actuó por su propia voluntad. Más tarde su ma-

8 Era probablemente el hijo (un segundón y por tanto deseoso de establecerse por el matrimonio) de un funcionario condal asentado en Brujas. En 1012, el castellano de Brujas recibe el nombre de Bertolf. En 1067 Erembaud padre de otro Bertolf posee el mismo oficio. El héroe de esta historia pertenecía probablemente al famoso clan cuyos miembros asesinaton a Carlos el Bueno en 1127 y no a la familia de Conon, señor de Oudenbourg y sobrino del obispo Radebod. Para esta áltima cuestión, cfr. N. HUYGHEBAERT «Un moine hagiographe: Drogon de Bergues-Saint-Winoc», Sacris Erudiri, XX, 1971, pp. 222. 
dre le reprendió por no consultarle a ella o a su padre. La censura fue correcta porque un buen matrimonio no era asunto individual sino familiar. A menos que fuera huérfano, como fue el caso de Eustaquio II de Boulogne, el joven debía dejar el asunto en manos de sus padres. La segunda irregularidad se dio porque los padres de Godelive «prefirieron a Bertolf por su dote (dos)». Era el más rico. Un matrimonio por dinero es un mal matrimonio. Aquí se expresa la sabiduría popular. Mal casados ya, la unión volvió a ser corrupta en la segunda fase, la definitiva. Bertolf llevó a Godelive a su hogar, es decir, al de su madre. Ésta vivía separada de su es. poso, tal vez repudiada por él y ambos alojaron a su joven hijo, o mejor fueron alojados por él. Cualquiera que fuera el caso, él podía tomar otra esposa; la cama matrimonial estaba vacante en la casa; lo que no ayudaba era que la madre estuviese allí. Aquí surge otro tema clásico - los lamentos por los mal casados. El viaje desde Boulogne hasta las afueras de Brujas fue demasiado largo, probablemente pasando la noche en route. Durante el viaje el demonio se clavó repentinamente en el espíritu del nuevo desposado quien concibió una gran «aversión» por su esposa. Naturalmente el caso de Felipe Augusto e Ingeborg viene a la memoria: no por ser un fracaso (la reina de Francia rechazó totalmente esto) sino por la inmediata repulsión. Bertolf se fortaleció en esta actitud por el largo discurso de su madre al llegar a su casa. *Todas las suegras, escrige Drogon, odian a sus nueras» (otra vez el pueblo hablando de sus costumbres a través de su boca y explicándolas). «Ellas son felices al ver casados a los hijos, pero inmediatamente sienten celos de su esposa». Esta mujer no sólo reprendió a su hijo por no haberle consultado sino también por lo que había escogido. La muchacha que había llevado a su casa además de ser extranjera era morena. «De modo que no hay cuervos aquí y allá para que vengas y te traigas a uno de un nido de otro país (in alia patria)». Entonces Bertolf se retira, rehusando tomar parte en la ceremonia del matrimonio (ordo nuptiarum). Se ausenta durante los tres primeros días de la fiesta ritual con el pretexto de negocios o justicia. Las apariencias fueron mantenidas, el júbilo fue fingido. Los ritos invertidos ya que una mujer, su madre, tomó el papel del esposo. Esta fue una transgresión al orden moral y sexual. Tal giro de eventos forman el argumento de una historia milagrosa. La corrupción de la unión se completó después de la ceremonia nupcial: apenas había retornado Bertolf cuando partió de nuevo, 
esta vez para estar con su padre. Su esposa quedó abandonada en el domicilio conyugal. Cumplió su papel como mejor pudo, manteniendo el hogar y dirigiendo a los sirvientes. Sin embargo estaba desolata. La soledad resultaba más opresiva por la noche y entonces rezaba. Durante el día hilaba y tejía. Pasaba el tiempo en tareas de monjas y beguinas, ansiosa de vencer la ociosidad, enemiga del alma, con el trabajo y la oración. El autor de la segunda versión (un benedictino) enfatiza estas palabras: «con este escudo, rechazaba los dardos de los sueños diurnos que comúnmente abruman al adolescente». La primera vita se esforzó en ser más convincente. El hagiógrafo se preocupó en asegurar que al quedar sola la joven no se volvió impúdica. Con tal fin, afirmó que ella nunca dio que hablar. Una precaución necesaria. ¿No era opinión generalizada que una mujer, y particularmente una joven, sucumbía fácilmente al pecado por ser de naturaleza depravada, sucumbía a la lujuria apenas se le quitaba el ojo de encima? Precisamente por esto, el esposo debería estar cerca de su esposa. Aquí se extiende el texto en una exhortación a los esposos. Ellos deben ser así, en la adversidad o en la prosperidad, soportando las cargas recibidas; estân obligados de jure a soportar su compañía, a vivir pacientemente (patienter) hasta la muerte, hasta que fueran dos en una sola carne; $o$, mejor dicho, «formaran un solo cuerpo por la copulatio conjugiiv.

Aunque pervertido, el vínculo no había sido desatado. Ahora Bertolf consultó a sus padres. Necesitaba deshacerse de su esposa. Efectivamente resulta digno de destacar que la idea de repudiarla no cruzara la mente de estas gentes diabólicas - acorde a estas edificantes narraciones. ¿Se había vuelto indecoroso en esta clase social echar a la esposa del hogar motu propio. De hecho fue planeado para alejar (deturpare) a la joven desposada; más exactamente y según las palabras de Bertolf, spara quitarle su colors. Se la sometió a pan y agua mientras los sirvientes se saciaban. Godelive no se consumió pues algunos vecinos por simpatía y algunas mujeres allegadas le proporcionaron alimentos en secreto (esto no fue un milagro, no hubo intervención divina, como ocurre siempre en las narraciones populares, lo hicieron personas completamente terrenales). No obstante se cansó de los insultos y alzó el vuelo. Esto era lo que todos esperaban. Dejar el hogar fue una transgresión y esta transgresión fue su desgracia. El monje Drogon no se dio cuenta de ello. Pero su colega, que arregló la primera 
versión, no se equivocó al admitir que Godelive había transgredido los «preceptos evangélicos», la prohibición de separar aquello que Dios había unido. ¿Cómo podía ser admitido esto por parte de una mujer que iba camino de ser santa? Entonces aparece la excusa: el terror físico (trepidatio carnis) que agita a muchos mártires. Este tipo de adición al manuscrito sugiere que la reputación de Godelive entre los clérigos no era al principio tan segura como para hacer innecesaria esta justificación. Por este motivo necesitaron rescribir y ampliar la biografia. Muerta de hambre, descalza, Godelive viajó a su país de origen. No fue sola, sino en compañía, ya que las mujeres que no eran libertinas debían ir con escolta por los caminos. Pidió juzticia, pero a través de su padre, ya que, además de ser menor de edad, no era apropiado a una mujer defender por sí misma sus derechos. La mujer delegaba la tarea en un hombre, sino era el esposo o el hijo, en un varón de su familia. Heinfridus la recibió bien y apeló al perverso señor del esposo, el conde de Flandes, de quien Bertolf era ministerialis. A partir de este punto, las dos hagiografias cambian de rumbo, cesan las prédicas morales y hablan acerca de la nueva ley - sobre la que la Iglesia trabajaba para que fuera admitida por la sociedad secular de finales del siglo XI. Ambas versiones - la segunda de un modo más vehemente - proclaman la exclusiva competencia de la justicia episcopal en las cuestiones matrimoniales. No he encontrado, en el norte de Francia, este derecho expresado tan explícitamente antes de este doble manifiesto, inserto en la historia de una esposa deshonrada. El monje Drogon pone en boca de un conde anterior un discurso dirigido al actual conde Roberto de Frisia. De este modo esperaba incitar al conde a conducirse con más decoro y a reducir sus prerrogativas como imaginaba que había hecho su predecesor. El buen príncipe proclamó su renuncia al derecho de juicio haciéndolo recaer en el obispo de la diócesis que entendía en materias de este tipo debido a que era, según sus palabras, de la «Cristiandad*? El prelado debía conseguir que aquellos que «se desviaban del orden santo* regresaran al camino recto - debían ser frenados por la discretio eclesiastica, por el anatema (se especi-

9 La expresión justicia christiamitas aparece en el mismo período en un docu. mento de Mầcon en relación con una división de jurisdicción entre un conde y un obispo: Cartulaire de Saint-Vincent de Mâcon, ed. C. Ragut (Mâcon, 1864), nủm. 589 . 
fica en la última versión), indicando claramente que esos casos sólo (solummodo) debían ser resueltos ante jueces de la Iglesia. «Yo sólo soy un auxiliar (adjutor), reconoció el conde. La segunda versión dice defensor (vindex). Concepto que se aplicó al rey de Francia cuando luchó con la espada temporal contra aquellos a quienes Dios a través de su iglesia había condenado. La autoridad (auctoritas) estaba en un lado, el poder (potestas) en el otro. (El monje de Dudenbourg que era un experto compara los dos términos entre sí). Esta perfecta división gregoriana afirma la superioridad de lo espiritual sobre lo temporal y sitúa el poder jurisdiccional de los obispos como extensión de las proclamas de la paz de Dios, que habían sido establecidas en aquella región en la generación precedente.

El obispo de Tournai decidió que Bertolf tomara a su mujer otra vez ya que no había adulterio, ni indicios de impotencia del marido, ni duda en la consumación del matrimonio. Un divorcio, de acuerdo con las normas recogidas en las colecciones canónicas, no podía pronunciarse. La mejor solución en este caso era la reconciliación de la pareja. Bertolf se sometió pero de mala gana. De acuerdo con la versión refundida esto se hizo por temor a una sanción secular. En su odio, en su disgusto, sólo encontró un camino: el crimen. Aquí comienza la pasión de Godelive - su pasión, paciencia y lenta evolución espiritual. La esposa no fue perseguida físicamente. Bertolf había prometido no maltratarla. Pero quedó abandonada incluso por su padre. Privada de hombre, lo cual resultaba un escándalo. Los parientes y amigos» de su esposo estaban traumatizados: lo criticaron, pero Godelive como digna consorte en la societas conjugalis prohibió a todos hablar mal de su esposo. La compadecen en particular por haber sido privada «del placer del cuerpo», pero ella les replica: «En nada aprecio los deleites de la carne». En su jubilosa constancia la ejemplar esposa tendió lentamente a despreciar las cosas mundanas. Asumió rasgos y actitudes propios de la Virgen. Las palabras del Magnificat le abrieron el camino en las conversaciones que mantenía sobre todo con los monjes de St. Winock que acudían a visitarla y a los que ella instruyó a pesar de ser una frágil mujer, ofreciéndoles un ejemplo de continencia y obediencia. Mientras aún resonaban los ecos de la liturgia mariana y el texto de los Evangelios, la narración da entrada al martirio.

Bertolf había preparado un plan. Lo dispuso todo con dos de 
sus sirvientes, buscando el consejo de esas personas de bajo nacimiento -otra corrupción. Una tarde, antes del ocaso, Godelive vio que se le acercaba; ella tembló mientras él le sonréía. La tomó en sus brazos, la besó y la sentó en su mismo cojín (en la postura que los retratistas parisienses del siglo XIV plasmaron para los amantes corteses en el marfil de los espejos y en las cajas de los perfumes). Atrajo a su esposa hacia él. Aunque temerosa, Godelive lo complació, estaba dispuesta a cumplir todos los deberes de la unión conyugal cuando el señor lo requisiera. Ahora, muy cerca de ella, Bertolf la adulaba: «No estás acostumbrada a mi presencia ni a ser cautivada con dulces palabras ni a compartir los deleites de la carnes (palabras y placer, en realidad son las dos fases sucesivas en el amor, en el juego del amor que debía ser jugado ritualmente). Pero «voy a poner punto final al divorcio del espíritu, tratándote como a una esposa querida y gradualmente dejar atrás el odio y sellar nuestras mentes y cuerpos bajo la unidad... He encontrado una mujer que se encargará de unirnos con un amor firme y constante, de hacernos amar una y otra vez sin interrupción y más de lo que cualquier pareja ha podido amarse sobre la tierra. Los dos sirvientes la condujeron a la bruja, entonces dijo Godelive: «Soy la sierva del Señor. A él me entrego. Acepto si esto se puede hacer sin delito». Y el hagiógrafo exclama: «iQué virtud!». Primero se puso en manos de Dios, temiendo ser separada de él por la magia. Esto es razonable ya que aescogió ese matrimonio para así no ser separada del Señor que une las parejas».

Si creemos en lo que dice Fr. Goens, editor de la primera versión, esta escena tuvo lugar el 30 de julio de 1070 . El 17 de julio el conde Balduino había muerto y sus súbditos se encontraban divididos: el pueblo de las costas de Flandes (territorios de Bertolf) de parte de Roberto de Frisia y los de Boulonais (Godelive) estaban con la viuda. Una gran confusión tenía lugar y ése fue el momento perfecto para la acción. Bertolf sale. La noche cae - es el tiempo del desastre, el tiempo del demonio. Los dos sirvientes van a buscar a la dama. La escoltan en una parodia de procesión nupcial hacia el demonio - en el silencio, en la profundidad de la noche, en el momento que los autores de historias populares sitúan los crímenes más negros. La condujeron desde la cama hasta la puerta, no hacia su marido sino hacia una mujer más espantosa que su propia suegra, una verdadera bruja. Godelive es estrangulada y lanzada al agua, como en un nuevo bautizo. Santificando el agua 
de modo que pudiera realizar milagros. Finalmente la llevan a su cama y la vuelven a vestir. A la mañana siguiente su gente la encontró aparentemente intacta. De inmediato se presentó la duda: una sospecha sólo susurtada porque había nacido entre los más pobres. De inmediato ocurrió un milagro: la multiplicación de los panes para la comida del funeral de nuevo en beneficio de los pobres. Más tarde el culto: el agua que cura - siempre a los pobres - y las piedras que se convierten en joyas.

Éste fue un culto que se burlaba de los dos poderes: el del obispo, porque el extraño poder de esta mujer mẩrtir hacía ineficaces las prohibiciones y los castigos que había decretado e impuesto; el del conde, porque zno es acaso el embustero de esta historia - el torturador - con sus sirvientes y secuaces un funcionario del conde, responsable de recaudar los impuestos?. Aún sin seguir a Jacques Le Goff en toda su hipótesis resulta imposible no percibir en la forma primitiva de este culto, en la estructura original de la le. yenda, una protesta en favor de los oprimidos, de todas las víctimas inocentes. La heroína provenía ciertamente de la clase privilegiada del sistema señorial. Las crueldades que le infligieron disminuyeron su honor y la atención a su rango. En todo caso era una mujer, es decir, un ser dominado a quien su marido mató de hambre, igual que hacía con los siervos de su señorío desde su situación de funcionario. Este culto, esta narración surgieron probablemente del pueblo, en el conflictivo sentido social de este término, y pueden ser considerados como una manifestación de la lucha de clases mantenida por el obstinado y libre campesino de las costas de Flandes en los tiempos de agitación de la sociedad señorial. Algunos años después, cuando el flamenco Arnulfo consiguió la reconciliación entre los grandes hombres de Flandes ${ }^{10}$, el conde (encabezando los juicios por asesinato cometidos en la tierra de Brujas) y el obispo (fundador de la abadía de Oudenbourg) llegaron a un acuerdo para neutralizar este culto y utilizarlo en favor del orden establecido. Así fue cómo la vida de una santa fue sustituida por la historia de la víctima de un mal matrimonio ${ }^{11}$.

10 Vita Arnuldi, II, 16 (Patrologiae cursus completus, ed. J.-P. Migne, Series latina, CIXXIX, Paris, 1854, col. 1413).

11 En relación con los textos de la vida de Godelive que he utilizado destacan algunos comentarios mantenidos en un simposio en 1970, en especial los de $H$. Platelle y E. Warlop. Las actas fueron publicadas en Sacris Erudiri, (1971). 
El orden establecido no sólo requería desviar los cultos para introducirlos en la ortodoxia. También se exigía la prescripción de reglas que debían ser observadas por las parejas. Los dos poderes acordaron imponer estas normas. El relato de los infortunios de Godelive reforzó las amonestaciones del matrimonio según dictaban las reglas. Esta exhortación presagiaba lo que la vita de la condesa Ida expresaría unos cincuenta años más tarde. La unión conyugal, atada por Dios, no puede ser desatada. Correpondía a los padres, y no a la gente joven, concluir el pacto y ellos debían tener en cuenta más la moral que la riqueza y evitar invidia, los celos, que destruyen las alianzas. Para que esto no ocurriese era mejor una esposa obediente como lo fue la Virgen María. A todo esto se añadieron las admoniciones, aunque en voz baja, de desprecio por la carne, de búsqueda del ideal en una vida devota basada, como el ideal de los herejes en el pasado y el ideal de las beguinas en el futuro próximo, en el trabajo de las manos, en la obstinación y en el temor al placer. Por otra parte, se impuso con firmeza que el derecho en un juicio matrimonial sólo concernía a los clérigos - ¿la conclusión de este último punto indica que se ha alcanzado ya el consenso entre los dos poderes?. En cualquier caso, ésta fue la base de la doctrina en la que los monjes fueron instruidos para promulgarla con moderación en esta zona a mediados del siglo. Desde estas perspectivas, estas obras, cuyo sentido e intención he tratado de analizar, exponen otras cuestiones concretas. Primero, ambos escritos tratan sobre mujeres. Tomar las figuras femeninas como portavoces de la ideología eclesiástica ofreció una doble ventaja. Con ellas se recuperó aquella parte de los cultos a los que la Iglesia no había prestado suficiente atención en el pasado y cuya importancia debía ser nuevamente valorada. Por otro lado, concentraron la atención en el pueblo de naturaleza pasiva a través de cuyo ejemplo grabaron con firmeza y profundidad los principios de una sumisión que se esperaba de todos los laicos. No obstante, el tono de las dos obras es diferente. Atribuyo esta diferencia al hecho de que uno va dirigido a la clase dominante y el otro hacia los dominados. En la vita de la esposa feliz, la condesa Ida, como en la mayor parte de las que se han conservado, $\mathrm{y}$ al ser dirigida a quienes la han encargado - los poderosos linajes, los cabezas de familia-, la exhortación pone énfasis principalmente en la función genética del cuerpo femenino. Al contrario, la leyenda de Godelive se dirige al pueblo, en cualquier caso procede de él, y 
por ello el acento está puesto en el Amor. Destaca el hecho de que en la biografía de la condesa Ida primen los términos derivados de la palabra genus, mientras que en la vita de Godelive la mayoría derivan de la palabra amor. Es obvio que este amor respeta la necesaria relación de subordinación que la providencia ha instituido entre los dos sexos; el amor del esposo hacia la esposa es denominado afecto, mientras que el de la mujer por su esposo es denominado reverencia. Se repite con frecuencia que hombre y mujer deben unirse tanto en sus carnes como en sus espíritus. Ellos mismos hacen este amor sin hacer mención de la castidad (castitas). Se trata de un amor tanto del cuerpo como del corazón que conduce al aprecio de los encantos del cuerpo femenino. Además se autoriza recurrir a la brujería si es necesario para establecer este amor en su forma más perfecta. Cuando el obispo de Noyon-Tournai difundió lo que había surgido de un sentimiento popular al elevar las reliquias de aquella joven morena de tez clara y gran atractivo, sin darse cuenta se aventuró mucho más de lo que la mayor parte de sus colegas habrian de hacer en tiempos venideros. 